\title{
Lipohypertrophy and lipoatrophy complicating treatment with highly purified bovine and porcine insulins
}

\author{
Paul G. McNally, Nigel I. Jowett, Jenny J. Kurinczuk, Richard W. Peck \\ and John R. Hearnshaw
}

The Leicester Royal Infirmary, Leicester LEI 5WW, UK.

\begin{abstract}
Summary: Lipoatrophy and lipohypertrophy were the most frequently reported local complications of conventional insulin therapy. Early reports following the introduction of highly purified insulins suggested a reduction in the frequency of lipohypertrophy and lipoatrophy. Since highly purified insulins have been in common usage for 10 years, the present frequency of these complications was assessed in a study of 281 insulin treated diabetics. Lipohypertrophy was recorded in $76(27.1 \%)$ patients including 3 with associated lipoatrophy. Lipoatrophy was found in $7(2.5 \%)$ cases ( 3 porcine and 4 bovine insulin treated), 4 of which had only ever used highly purified insulins. Despite the introduction of highly purified insulins, lipohypertrophy and lipoatrophy remain prevalent in insulin treated patients. This common complication may be limited by routinely inspecting injection sites.
\end{abstract}

\section{Introduction}

Lipohypertrophy and lipoatrophy were the most frequently reported local complications of insulin therapy in patients treated with conventional unpurified insulins. ${ }^{1,2}$ Lipoatrophy is most commonly seen in children and women soon after the initiation of insulin treatment, and is characterized by loss of subcutaneous fat at the site of injection. In contrast, lipohypertrophy is marked by prominent fatty swellings at the site of repeated injections.

Early reports following the introduction of the highly purified insulins found a reduction in the incidence of lipoatrophy, although the frequency of lipohypertrophy remained unchanged. ${ }^{3,4}$ Nevertheless sporadic cases of lipoatrophy have been reported with both highly purified bovine and porcine insulins. ${ }^{5,6}$

Since highly purified insulins have now been in common use for 10 years, we have examined the injection sites of our insulin treated patients for evidence of lipohypertrophy and lipoatrophy to establish the present frequency of these potentially avoidable complications.

\section{Methods}

The injection sites of $281(151 \mathrm{M}: 130 \mathrm{~F})$ consecutive

Correspondence: P.G. McNally B.M., M.R.C.P., Renal Unit, Leicester General Hospital, Gwendolen Road, Leicester LE5 4PW, UK.

Accepted: 5 July 1988 insulin treated diabetics attending a diabetic clinic over a 3 month period were examined (by PGM and NIJ) for abnormalities. These were classified as lipoatrophy (sharply defined disappearance of sub-ç cutaneous fat without inflammation), lipohyper-? trophy (visible and palpable fatty swellings) and superficial fibrotic nodules (small raised lesions related to the intradermal injection of insulin). All patients had used highly purified insulins for 6 months or longer. Details of the types of insulin in use, as well as those in the past were obtained from the patient and verified by the medical records. Patients were asked if they regularly rotated their injection sites, and if they were aware of the local complications of insulin therapy. A glycosylated haemoglobin was performed to assess recent glycaemic control.

\section{Results}

Insulin-induced lipohypertrophy or lipoatrophy was recorded in 80 patients $(28.5 \%)$, with no difference in the incidence between sexes $(42 \mathrm{M}: 38 \mathrm{~F})$. Fiftyfive of these patients were currently using purified porcine insulins, 22 patients purified bovine insulins and 3 patients human insulins. The mean duration of treatment using highly purified insulins was 5.5 years (range 0.5-9 years). Fifty-two patients $(65 \%)$ had previously used unpurified insulins, with 21 $(40 \%)$ of this group developing lipohypertrophy (18

(C) The Fellowship of Postgraduate Medicine, 1988 
cases) or lipoatrophy ( 3 cases) when injecting these insulins.

Seven cases of lipoatrophy were recorded, with 3 patients using highly purified porcine insulins, and 4 cases following purified bovine insulins. In 3 cases lipoatrophy had complicated unpurified insulin therapy, but the other 4 cases had only ever used purified insulins. Lipohypertrophy was recorded in 76 patients, including 3 with associated lipoatrophy (Table I). The preparation of insulin used is shown in Table II. Superficial fibrotic nodules were seen in 9 patients.

Table I Clinical details of patients studied $(n=281)$

\begin{tabular}{lccc}
\hline & Lipoatrophy & $\begin{array}{c}\text { Lipo- } \\
\text { hypertrophy }\end{array}$ & $\begin{array}{c}\text { Normal } \\
\text { sites }\end{array}$ \\
\hline $\begin{array}{l}\text { Number (\%) } \\
\text { Sex (M:F) }\end{array}$ & $7(2.5)$ & $76(27.1)$ & $201(70.4)$ \\
& $3: 4$ & $40: 36$ & $111: 90$ \\
$\begin{array}{l}\text { Mean age in } \\
\text { years (age range) }\end{array}$ & 61.6 & 40 & 46.3 \\
& $(40-76)$ & $(11-82)$ & $(7-86)$ \\
$\begin{array}{l}\text { Mean duration of } \\
\text { insulin treatment } \\
\text { in years (s.d.) }\end{array}$ & $11.6(10.0)$ & $14.3(9.8)$ & $9.4(9.7)$ \\
$\begin{array}{l}\text { Number without } \\
\text { regular injection } \\
\text { rotation (\%) }\end{array}$ & $4(57.1)$ & $46(60.5)$ & $112(55.7)$ \\
$\begin{array}{l}\text { Number with } \\
\text { knowledge of } \\
\text { local complications } \\
\text { at injection } \\
\text { sites (\%) }\end{array}$ & & & \\
$\begin{array}{l}\text { Mean glycosylated } \\
\text { haemoglobin \% } \\
\text { (s.d.) }\end{array}$ & $4(57.1)$ & $43(56.6)$ & $117(58.2)$ \\
$\begin{array}{l}\text { Never used } \\
\text { unpurified } \\
\text { insulins (\%) }\end{array}$ & $8.5(2.2)$ & $9.5(2.6)$ & $9.2(2.4)$ \\
\hline & & & \\
\end{tabular}

Table II Preparation of insulin injected

\begin{tabular}{|c|c|c|c|}
\hline \multirow[b]{2}{*}{$\begin{array}{c}\text { Insulin preparation } \\
\text { injected }\end{array}$} & \multicolumn{3}{|c|}{ Number $(\%)$ of patients with: } \\
\hline & Lipoatrophy & $\begin{array}{c}\text { Lipo- } \\
\text { hypertrophy }\end{array}$ & $\begin{array}{l}\text { Normal } \\
\text { sites }\end{array}$ \\
\hline $\begin{array}{l}\text { Soluble insulin } \\
\text { alone }\end{array}$ & - & $5(42 \%)$ & $7(58 \%)$ \\
\hline Isophane insulin & $1(0.5 \%)$ & $62(26 \%)$ & $172(73.5 \%)$ \\
\hline $\begin{array}{l}\text { Insulin zinc } \\
\text { suspension }\end{array}$ & $6(18 \%)$ & $6(18 \%)$ & $22(64 \%)$ \\
\hline
\end{tabular}

\section{Injection routine}

Forty-eight of the patients $(60 \%)$ with lipohypertrophy or lipoatrophy had no regular routine for rotating their injection sites, and only $59.0 \%$ were aware that repeated injection into a limited area could lead to local complications. No difference in injection practice or knowledge concerning local complications following insulin therapy was seen in those with normal injection sites. Table III shows details of the injection practice of the patients studied.

\section{Glycaemic control}

The mean glycosylated haemoglobin of patients with abnormal injection sites was $9.55 \%$ (s.d. 2.62 , normal range 4-8.5\%) which did not differ significantly from the patients with normal injection sites $(9.22 \%, \quad$ s.d. 2.4 ; Mann-Whitney $U$-test, $P=0.24)$.

\section{Discussion}

Lipohypertrophy and lipoatrophy remain a frequent complication of insulin therapy in diabetic patients, despite the introduction and common usage of highly purified insulins. One third of the patients studied had evidence of either lipoatrophy or lipohypertrophy at their regular injection sites. The incidence of lipohypertrophy $(27.1 \%)$ is similar in frequency to that found by other workers. ${ }^{2,4}$ Most patients with lipohypertrophy admitted to restricting their injections to anatomically small regions, as the fatty swellings were convenient areas

Table III Injection practice of patients studied

\begin{tabular}{lllr}
\hline & Lipoatrophy & $\begin{array}{c}\text { Lipo- } \\
\text { hypertrophy }\end{array}$ & \multicolumn{1}{c}{$\begin{array}{c}\text { Normal } \\
\text { sites }\end{array}$} \\
\hline $\begin{array}{l}\text { Injection site used } \\
\text { regularly }\end{array}$ & & \\
$\quad$ Arm & $5(71 \%)$ & $26(34 \%)$ & $63(31 \%)$ \\
$\quad$ Leg & $7(100 \%)$ & $67(88 \%)$ & $171(85 \%)$ \\
$\quad \begin{array}{l}\text { Abdomen } \\
\text { Buttocks }\end{array}$ & $2(29 \%)$ & $20(26 \%)$ & $85(42 \%)$ \\
$\begin{array}{l}\text { Number using one } \\
\text { anatomical region } \\
\text { only (e.g. legs) }\end{array}$ & $1(14 \%)$ & $14(18 \%)$ & $24(12 \%)$ \\
& & & \\
$\begin{array}{l}\text { Number using two } \\
\text { anatomical regions }\end{array}$ & $4(57.1 \%)$ & $25(32.9 \%)$ & $63(31.3 \%)$ \\
$\begin{array}{l}\text { Number using } \\
\text { three or more }\end{array}$ & & & \\
anatomical regions & $2(28.6 \%)$ & $11(14.5 \%)$ & $36(17.9 \%)$ \\
\hline
\end{tabular}


to aim for, and were less painful for injection (Figure 1). The prevalence of lipoatrophy $(2.5 \%)$ recorded in our patients on purified insulin therapy has not been reported before. No cases of lipoatrophy were reported by either Wright et al. ${ }^{2}$ or Young et al. ${ }^{4}$ in patients treated with purified porcine insulins. Although sporadic cases of lipoatrophy have appeared in the literature in patients using both purified bovine and porcine insulins, ${ }^{5-7}$ the results of our survey suggest that lipoatrophy may still be a clinical problem (Figure 2). Previous studies identified young female patients as the high risk group for developing lipoatrophy, ${ }^{1}$ but no such association was seen in this survey, where the average age was much older and occurred with a similar frequency in both sexes.

Although patients are frequently advised to rotate their injection sites to prevent or limit the development of lipohypertrophy or lipoatrophy, true rotation using more than one anatomical site was seen in only $50 \%$ of those studied. No increase in the frequency of local complications was seen however in those patients who restricted their injections to one anatomical site, which suggests that if rotation takes place within one anatomical area then lipohypertrophy or lipoatrophy will not necessarily result. $^{8}$ Indeed an improvement in metabolic control may ensue in some patients if they restrict themselves to one region only, since the absorption of insulin may vary considerably between anatomical sites. ${ }^{9}$

The development of superficial fibrotic nodules reflects faulty injection technique, which therefore needs to be reviewed. These lesions may not only be painful but can lead to poor diabetic control,

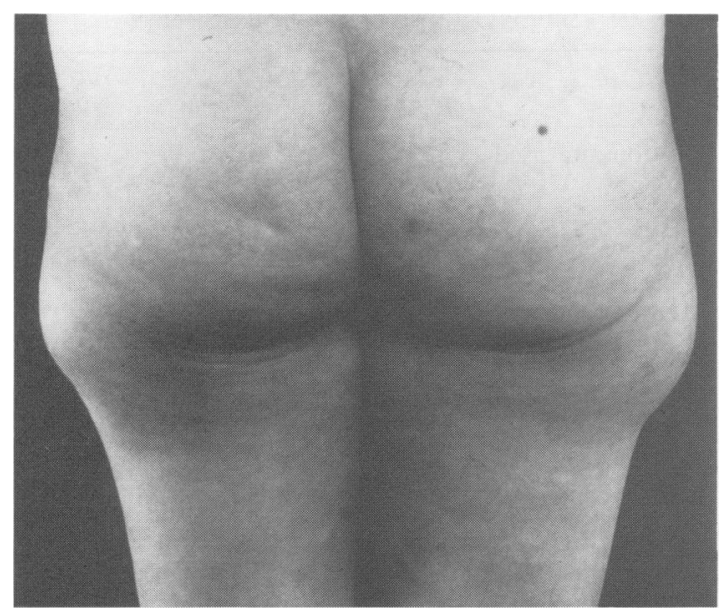

Figure 1 Lipohypertrophy complicating treatment with highly purified porcine insulin.

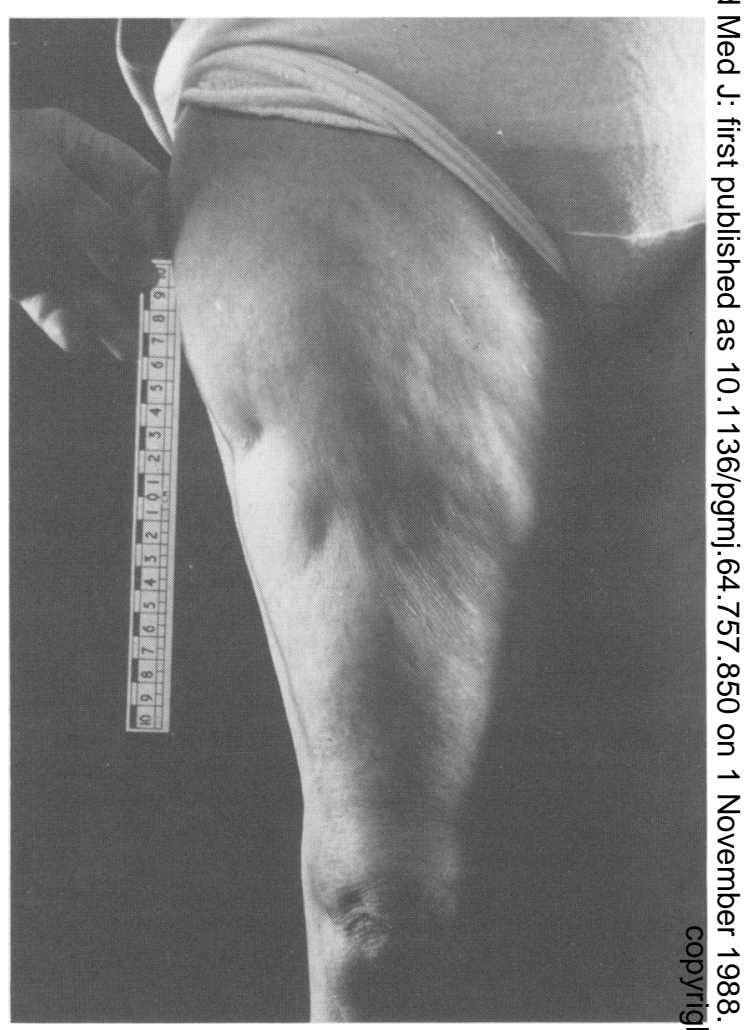

Figure 2 Lipoatrophy complicating highly purifiec $\bar{F}$ porcine insulin.

following leakage of insulin onto the surface of the $\frac{\mathbb{D}}{\Phi}$ skin.

The pathogenesis of lipoatrophy is not clearly $\overline{\bar{O}}$ established although Reeves et al. ${ }^{10}$ suggested a local immune reaction following the demonstration of immune complexes, complement fixation and inflammatory mediators at the site of atrophy. Furthermore the presence of zinc or fish protamine in modified insulins may provide a readily available 3 . source of antigen and enhance the immunological 8 reaction to insulin. ${ }^{11}$ The majority of patients with lipoatrophy in this study (85\%) were using a zinco based preparation. In contrast, lipohypertrophy is regarded as due to a local anabolic effect of insulin promoting fat and protein synthesis. ${ }^{12}$ It is probable that the constant injection of insulin into $\mathbb{N}$ the same area is the important factor in producing N hypertrophy rather than the actual dose of insulin injected. ${ }^{13}$

Absorption of insulin from areas of lipohypertrophy or lipoatrophy (especially lipohypertrophy) is variable due to the formation of fibrous scar tissue at the injection site, and may lead to poor? 
glycaemic control, since these relatively avascular areas may delay absorption. ${ }^{14,15}$ This variability of insulin absorption may manifest as periods of subclinical or overt hyperglycaemia and hypoglycaemia, which might explain why no significant difference was seen in the glycosylated haemoglobin concentration between those with hypertrophied sites and those with normal sites. However, wide swings in blood glucose levels are clearly undesirable.

\section{References}

1. Renold, A.E., Winigrad, A.I. \& Martin, D.B. Diabete sucre et tissue adipeux. Helv Med Acta 1957, 24: 322-327.

2. Wright, A.D., Walsh, C.H., Fitzgerald, M.C. \& Malins, J.M. Very pure porcine insulin in clinical practice. $\mathrm{Br}$ Med J 1979, 1: 25-27.

3. Teuscher, A. Treatment of insulin lipoatrophy with monocomponent insulin. Diabetologia 1974, 10: 211-214.

4. Young, R.J., Steel, J.M., Frier, B.M. \& Duncan, L.J.P. Insulin injection sites in diabetes - a neglected area? $\mathrm{Br}$ Med J 1981, 283: 349.

5. Evans-Jones, L.G. Lipoatrophy in a patient on highly purified beef insulin. Arch Dis Child 1982, 57: 638-639.

6. Jones, G.R., Statham, B., Owens, D.R., Jones, M.K. \& Hayes, T.M. Lipoatrophy and monocomponent porcine insulin. $\mathrm{Br}$ Med $J$ 1981, 282: 190.

7. Jowett, N.I. \& McNally, P.G. Lipoatrophy with highly purified insulins and treatment with recombinant human insulin. Practical Diabetes 1988, 5: $130-131$.

8. Burden, A.C., Jones, G.R. \& Blandford, R.L. Insulin injection technique and diabetic control. Practical Diabetes 1984, 1: 10-12.
Local complications following highly purified bovine or porcine insulins are still common in insulin treated diabetics. Poor injection sites are not only unsightly, but may also lead to poor glycaemic control. ${ }^{10}$ Highly purified insulins provide no guarantee against lipohypertrophy and lipoatrophy, which may be limited by routinely inspecting injection sites at clinic visits.

9. Koivisto, V.A. \& Felig, P. Alterations in insulin absorption and in blood glucose control associated with varying insulin injection sites in diabetic patients. Ann Int Med 1980, 92: 59-61.

10. Reeves, W.G., Allen, B.R. \& Tattersall, R.B. Insulininduced lipoatrophy: evidence for an immune pathogenesis. Br Med J 1980, 280: 1500-1503.

11. Reeves, W.G. Immunology of diabetes and insulin therapy. In: Thomson, R.A. (ed) Recent Advances in Clinical Immunology. Churchill Livingstone, Edinburgh, London, New York, 1980, pp 183-220.

12. Renold, A.E., Marble, A. \& Fawcett, D.W. Action of insulin on deposition of glycogen and storage of fat in subcutaneous tissue. Endocrinology 1950, 46: 55.

13. Meier, A., Weerakoon, J. \& Dandona, P. Bilateral $\bigcirc$ abdominal lipohypertrophy after continuous sub-뭉 cutaneous infusion of insulin. $\mathrm{Br} \mathrm{Med} J$ 1982, 283: 1539.

14. Bressler, R. \& Galloway, J.A. Insulin treatment of diabetes mellitus. Med Clin North Am 1971, 55: 860-876.

15. Young, R.J., Hannan, W.J., Frier, B.M., Steel, J.M \& Duncan, L.J.P. Diabetic lipohypertrophy delays insulin absorption. Diabetes Care 1984, 7: 479-480. 